\title{
MOMENTUM INVESTING STRATEGY IN IDX: AN EXPERIMENT
}

\author{
Ronald W. Liem ${ }^{1}$ \\ UBS Indonesia
}

\begin{abstract}
This research aims to test whether the Momentum investing strategy is better than passive investing strategy. The research method used is experiment design. The population observed is Kompas 100 shares. The sample is filtered using several iterations based on the market performance as the momentum points and other fundamental factors to form optimal portfolios. The data used is the quarterly data. The ttest and Mann-Whitney means difference tests are performed to assess the differences of the results of momentum strategy and the market. The results show that momentum strategy provides higher returns than the market does.This experiment suggests that momentum investing strategy is applicable in IDX.
\end{abstract}

Keywords: momentum, investing strategy, markowitz, IDX.

\section{INTRODUCTION}

Fama (2006) argued that there is a short-term momentum in stock returns, in which that the return pattern for the last six months seems to repeat in the future. Momentum investing is one of the active portfolio strategies. It relies on the continuation of a trend. Initially, the momentum-investing style is only applied to price momentum as branch of technical investing. However, it evolves to include the momentum in the fundamental account of the company like earning momentum, sales momentum, and many others.

\footnotetext{
${ }^{1}$ UBS Indonesia (rwiryaman@jwc.binus.ac.id)
} 
The roots of momentum strategy can be traced back to the behavioral finance. According to behavioral finance, momentum investing is a result of investor reaction to specific news and their behavior as explained in the prospect theory. Investors could under/over act towards specific news. Investors are categorized as underact if a group of investors does not fully price a new information. In contrary to the undereaction, investor overreaction is happened when a group of investors drives the price of asset more than the supposed price impact from new information.

According to the prospect theory of Kahneman and Tversky (1979), investors tend to sell the winning too early and tend to hold on losing stock too long. This behavior is responsible for the gap between the stock and the fundamental value of the company. However, the market price in the long term will converge again with its underlying fundamental value. The process of convergence will appear as momentum.

According to Hong and Stein (1999), investors' undereaction and overeaction are a series of related events. If there are two groups of traders, the first group undereact to private information, and the second group observes that the first group undereacst the information, the second group will arbitrage the gap between the current price and the full potential of the price movement. By doing so, the second group already create price momentum to the asset, which will be followed by other groups. This will result in overreaction.

Momentum investing is against weak-form market efficiency. It uses past performance as inferential of future performance. Meanwhile, the weak form efficiency states that no investor can outperform the market by using past information since it is already reflected at the current price.

Compared to the conventional idea of buying-low, sell-high strategy, the momentum investing differs by looking for the stocks that are already increasing in price. For momentum investing, buying at low price is not neccesary as long as there is upward trend formation. Although Driehouse is not the first investment bankers who applied the strategy, his decision to use the strategy for mutual fund in 1982 through Driehaus Capital Management, Inc. was seen as the start of 
momentum investing strategy in practice. In their seminal paper on the momentum investing, Jegadeesh and Titman (1993) argue that momentum on the price movement does exist. They found that the increasing stock price tends to reproduce its upward movement and it is valid for a 3-12 months investing horizon.

Indonesia is currently one of the fastest growing market in the world. Recently, Bank of Indonesia announced that there was a trend of heavy inflow of foreign money to Indonesian capital market. This inflow of money will surely increase the market capitalization, as we can see that as of 10 November 2011, our index has touched its high level record of 3,757 .

On the other hand, there is also an increasing trend of local investors' interest in participating in the capital market. AC Nielsen research finds that there is strong growth in equity or mutual funds investment which comes from young professional discretional income in recent year. There is also a growing supports in forms of many platforms available to conduct securities online trading such as Etrading, DONE (Danareksa), KES (Kim Eng), and AMClick (AM Capital). These platforms offer low cost service with minimum interaction, guidance, or research. The increase of new investors who open online trading accounts will raise the risk of increase in market volatility and decrease of rationality. Thus, there is a need of a simple investment strategy to follow. Momentum investing strategy could be one of the alternatives that this research aims to explore further.

This research is an experiment study applying the momentum investing method in Indonesian stock exchange. It aims to compare the momentum investing strategy and the passive market method in Indonesia stock market, based on four factors: Revenue growth, Operating income growth, ROE, and Relative Strength Index. The experiment uses the data from Q1 2006 to Q2 2010.

\section{THEORETICAL FRAMEWORK}

\section{Portfolio management and strategy}

Portfolio theory is one of the major innovations in the realm of finance. It is more than just a combination of the investments. 
According to the portfolio theory, the relations between the constituting investments will determine the risk and return profile. The combined risk and return profile will differ than the sum of the parts.

This theory is developed under a basic assumption of that every investor wants to get the highest return from a set of investments at a given level of risk. Risk in portfolio is defined as the uncertainty of future return. Variance and standard deviation are the most commonly used gauge to measure risk.

The quest of portfolio theory is to minimize risk and maximize return through optimum combination of investments. Summarizing Ibbotson and Kaplan (2000), Brinson, Singer and Beebower (1991), and Brinson, Hood, and Beebower (1986), Reilly and Brown (2006) pointed out that about $90 \%$ of the portfolio return can be explained by its target allocation policy. A portfolio can be optimized to maximize return and minimize risk. According to Markowitz (1965), by optimizing weighting in the portfolio, investors can achieve their expected return with the lowest risk.

There are two types of portfolio management. One is active management and the other is passive management. The passive one believes that fully diversified portfolio will give better return per unit risk and that the market is unbeatable in average. In contrary to passive management, the active one believes that the market is beatable by give additional focus on the investment that has more likelihood of higher return.

According to Rilley (2006), active portfolio strategy can be divided into three major categories: 1) fundamental investing, 2) technical investing, and 3 ) anomaly and attributes.

Fundamental investing is top down (asset class, geographical, and sectoral rotation) or bottom up analysis (corporate valuation). It is straight forward, but requires a lot of time, effort, and knowledge. Technical investing mainly consists of contrarian and price continuation, which similar to momentum investing. Anomalies and attribute includes specific strategy to exploit market anomaly like calendar effect, fundamental momentum, low $\mathrm{P} / \mathrm{E}$, low $\mathrm{P} / \mathrm{B}$, and other event driven theme like merger $\&$ acquisition arbitrage. 
If momentum investing only includes price momentum, it is in fact a part of technical investing strategy. However, if it is combined with fundamental momentum, then it falls to anomaly and attribute strategy category.

Many researches compare between technical investing, value investing, and momentum investing. It is because these three strategies can offer alternative to the laborious fundamental investing. It helps fund managers to be able to systematically filter wide range of stocks. One fund manager can cover 500-1,000 stocks across borders. This will make them impossible to do real fundamental analysis on the stocks.

\section{Momentum Investing}

The Momentum investing strategy is a strategy with a principle of investing on past winner and short selling (if allowed) past loser (Jegadeesh et al, 1993). The momentum investing strategy acknowledges that there is persistant trends in price movement (technical anaylis), but it also involves a fundamental analysis to work. For example, Bird and Casavechia (2007) incorporate company's earning with their price momentum.

According to Griffin et al (2005), momentum strategy's profit is significant and statistically reliable around the world in both good and bad economic environment. Moreover, Grundy \& Martin (2001) argue that momentum strategy's profit is stable and applied to all sub periods after 1926.

Conrad \& Kaul (1998) state that the winner minus loser returns will remain positive for longer periods, which implies that momentum investing can exploit this long term trend and that the winner will remain winners and that losers will remain the same. However, Jegadeesh and Titman (1993) find that this winner-loser returns will start to decrease after twelve months

The momentum investing strategy is based on the new information released by the companied. Bernard (1992) shows that the earning announcement is the key factor to move the stock prices. While Chan, Jegadeesh \& Lakonishok (1996) prove that market risk, size and book to market effects do not explain the stock price movement, but an 
earning surpise does. The implication of momentum investing is that if we detect the momentum soon after the company announcement and wait until the analysts gradually absorb the new information, the stock prices will increase along with an increasing demand. Similar to the findings of Chan, Jegadeesh \& Lakonishok (1996), La Porta (1996) find that the group value stocks do not have higher risk compared to the growth stock. They also stated that the main driver is the recent result announcement and earnings surprises.

In accordance with Jegadeesh and Titman (1993), the momentum strategy is valid for 3-12 months investing periods. This period is enough to rebalance quarterly portfolio rather than monthly, weekly, or even daily. In the report, they compared the hold strategy's performance to the momentum investing based on result announcement. The result was the momentum investing strategy produce $8.8 \%$ higher return compared to the buy and hold strategy over six months period. It applies to both direction by buying stock with positive momentum and short selling the ones with negative momentum.

The underpinning actions of momentum investing are "imitating others" characteristic and having difference time horizon in processing information. Similar finding by Hou (2001) shows that in general, slow information diffusion in the industry is one of the sources of momentum investing profit. The example of herding characteristic is that in the good year, people have very optimistic view ahead and willing to pay higher price on prospective stock. Herding is a natural phenomenon in human psychology and one of the main study topics in behavioral finance. Meanwhile, the time horizon difference can be illustrated in the following example: a trader can get access to newly published information faster than individual investors can. Thus, they can trade first and start to build up momentum, in which will be followed by individual investors.

The momentum investing can be an alternative to the value investing for it requires less information and skills of the analyst. There are several stocks' characteristics that could be used as indicators for the momentum investing. Lee and Swaminathan (2000) find that momentum investing is much more prevalent to stock with high average daily value traded. In addition to that, Hong, Lim, and Stein 
(2000) find that the momentum investing is very effective among small firms with low analyst coverage. Grinblatt et al (2003) state that momentum investing is well applied on small firm with small institutional owner, growth firms and high volume stocks. However, there are critics to momentum investing that trading cost can be substantial when frequent portfolio rebalancing chases dynamic momentum (O'Shaughnessy, 2004).

According to O'Shaughnessy (2004), the most prominent disadvantage of the momentum investing is the trading cost. One of the trading cost components is the trading frequency, and the other is the upward stock price increase due to abrupt increase in demand. The later is a function of value traded toward average daily turnover of the particular stock. This research tries to reduce the first component of trading cost by only rebalancing the portfolio every quarter on a new result. For the second trading cost component, it would be much less to the retail investor, which is our target audience, due to their trading size.

As founded by Bird and Casavecchia (2007), even to invest in value stock, investors still need to rely on momentum or market swing to take position on the stock. According to their research, the momentum investing is evidentially improves the portfolio return by $2.6 \%$ and $2.4 \%$ for value and growth stock respectively.

As mentioned before, the momentum is driven by several factors. According to Patel (2008), the company with strong sales growth has an alpha value. Thus, a portfolio can profit from long on positive sales growth company and shorting the one with negative sales growth. The second factor used as a base for a momentum is operating income (pretax profit). Reinganum (1988) observed characteristic of winner stock from period 1970 to 1983 . The author found that the winners share common characteristic is the winner experienced $2 \%$ average increase in pretax profit prior ther following rapid price appreciation.

The next factor observed for a momentum is Return on equity (ROE). According to Damodaran (2002), return on equity (ROE) has an implication to growth rate assumption. Moreover, it also determines the price-earning multiple of the stock. Thus, ROE filter in this study 
will be used to select companies with high growth propensity and also high price earning multiple.

The final momentum factor used in this study is Relative Strentg Index (RSI). Most of momentums investing research focus on price movement momentum. Bird and Casavechia (2007) incorporate momentum on company earnings with price momentum. Their findings prove that the momentum links to that of fundamental components, such as earning. Furthermore, they incorporate conventional price / technical momentum with fundamental momentum of earning. This research introduces the relative strength index (RSI) that combines fundamental and technical momentum methods. Following Bird and Casavechia (2007).

\section{RESEARCH DESIGN}

\section{Population and Sampling}

This research uses Kompas 100 because the index only select liquid, high market capitalization, good fundamental, and good performance stock. Kompas 100 index is designed to represent $70-80 \%$ market capitalization in Indonesia Stock Exchange.

According to Indonesia Stock Exchange, the selection factors of Kompas 100 are considered as follows:

1. Have been listed for at least 3 months

2. Volume transaction, value traded and trading frequency

3. Number of trading days in the exchange

4. Fundamental factor and trading pattern

5. IDX take full responsibility to make sure that the stock selection is for best interest of investor and other stakeholders.

Based on above mentioned factors, the author view Kompas 100 as a representative population of investable stock and still represents $25 \%$ of all stock listed in IDX (410 stocks in total). This research selects only investable stock as the stock population on the basis that the stocks which have higher capitalization and value traded have lower non-commission trading cost. Non-commission trading cost are the stock price elasticity to the volume demand, and bid/ask spread. Non liquid and small capitalization stocks have higher elasticity and higher 
bid/ask spread. Thus, only the investable stock population is chosen in order to ensure the research method closer to real trading situation.

From Kompas 100 stock 2007 data, the sample are filtered again to only include companies that are already listed in 2004 to provide 2 year minimum monthly price data in order to construct variance covariance matrix for the portfolio construction in year 2006. Out of 100 companies, 23 companies were not yet listed in 2004 and another 22 companies have severe data deficiency in ROE and RSI.

Table 1. Sample Derivation

\begin{tabular}{|l|c|}
\hline \multicolumn{1}{|c|}{ Sample Group } & Number of stocks \\
\hline Population Kompas 100 in 2007 & 100 \\
\hline Not yet listed in 2004 & 23 \\
\hline Missing ROE data & 11 \\
\hline Missing RSI data & 11 \\
\hline Final sample & 55 \\
\hline
\end{tabular}

The next step is to construct the optimal portfolio using the Markowitz optimization and portfolio performance simulation, which will be compared to the market capitalization weighting of the stock population and see whether the outperformance or alpha exists. If it does not exist, it could mean that momentum investing does not work in Indonesia or that selecting factors is probably inappropiate. The alpha value still needs to be tested for statistical significant level. 


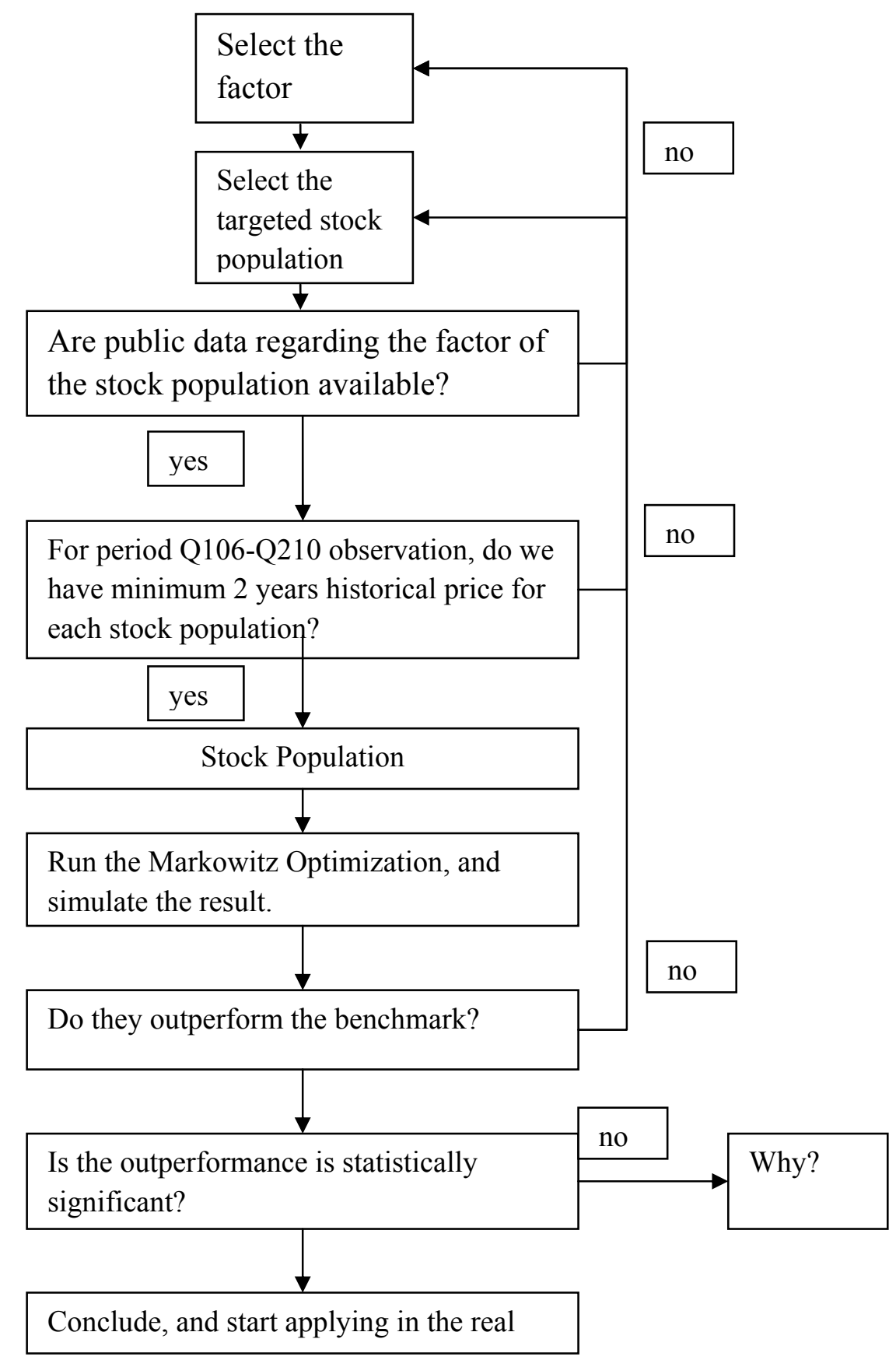

Figure 1. Thinking Process Chart 
According to Khan and Grinold (1994), there are four generic steps to construct a portfolio:

\section{Screening}

In screening process, the stock population is categorized according to their ranks in the respective factors. In this research, the respective factors are revenue growth, operating income growth, ROE and 30 days RSI (RSI 30D). Then we can give them rank according to quintile. The total score will be equally weighted. The objective is to create buy and sell list.

\section{Stratification}

Stratification step is still very effective to reduce bias. It is useful if a standard cannot be applied to different sector due to principal difference. What stratification does is basically to regroup the stock population into several category, for instance based on sector. Therefore, the ranking process can be adjusted as relative to its peer. Stratification can solve problem like in the case if the research use PBV as a factor, stock that come from banking sector will tend to fill the lowest PBV group, or gross margin on commodity trading company and brokerage firm which always fill the lowest gross margin group.

However, this research does not require stratification since the factors selected are can be applied across sector. These factors do not contain sectoral or industrial characteristic, i.e. regardless the industry, $30 \%$ revenue growth is a strong number while $4 \mathrm{x}$ price to book can be good or bad numbers for different industry.

\section{Linear Programming}

Linear programming is an optimization part of the process. In this stage it can accommodate additional constraint, for example maximum weighing on particular stock or sector in the portfolio to ensure diversification, maximum overweighting and underweighting level, transaction cost, etc.

This research use linear programming for its robustness and simplicity. The linear programming in this model optimize sharpe ratio of the portfolio in every periods to determine the portfolio weighing. The constraints are:

a) No short selling, which means that the weighting has to be positive. 
b) Weighting range : $1 \%-20 \%$ for paticular stock. This is to maintain certain diversification level.

\section{Quadratic Programming}

Quadratic programming applies linear constraint on quadratic objective function. It can accommodate all the constraint in linear programming and can be explicitly taken into account alpha, risk and transaction cost simultaneously. However, it requires many more high quality data so that it increases the risk of "garbage in garbage out".

Nevertheless, this research will not use the quadratic programming. It directly maximizes the Sharpe ratio. This is a straight forward method, while normally quadratic programming work on by optimizing the variance and covariance of each stocks.

According to Khan et al (1991), this research classifies factors/criteria in constructing a portfolio into three categories:

\section{External influence factor}

External influence factors are the factors that do not inherent in the associated stock. Sample of these factors are inflation rate, GDP level, bond yield, etc.

\section{Cross sectional factor}

All factors those are associated to the stock, for example, company's earnings, revenue, $\mathrm{P} / \mathrm{E}, \mathrm{PBV}$, etc.

\section{Statistical factor}

It covers aspects like principal component analysis, maximum likelihood analysis, expectation maximization analysis etc. As the name suggest this factor put emphasis on stastical property of the measures instead of the magnitude of the measures itself. For example instead choosing the companies with highest sales growth, it choose the companies with higher sales growth stability i.e lower standard deviation or choosing stock price that have highest alpha compared to the market index.

This research uses three fundamental criterias and one technical criteria. For fundamental criteria, it chooses higher four quarter revenue growth, higher four quarter operating income growth, higher 
ROE. For technical momentum gauge it uses Relative Strength Index (RSI). All measures of the variables will be explained in the data analysis section

\section{DATA COLLECTION METHODOLOGY}

This research uses primary data of quarterly result of the stock population from first quarter 2004 (Q104) - first half 2010 (H110). The data is retrieved from the Bloomberg database.

The price data used is stock price at end of the month after the quarter ends. One month is normally the time that a company would need to issue their quarterly report to the public. This one month duration may give bias on the companies which issue limited review version, that is due to longer deadline set by Bapepam for the limited review and audited financials statement.

However, in general the companies that will issue limited review or audited financials give preliminary result guidance to the public. Usually, this guidance is not far off from the reported result. Therefore, one month delay for stock price data is quite fair as a proxy for the market's reaction to the quarterly result.

\section{Data analysis}

\section{The Optimal Risky Portfolio}

After settling on the list of good stock to buy, it is necessary to determine the optimal weight of each stock on our portfolio by using the Markowitz optimization process. Portfolio optimization's goal is to reduce the unsystematic risk, so that the portfolio will have lower systematic risk than sum of the parts.

The source of diminishing risk in the combination of risky asset or stock is the correlation between the stocks. Some of them are positively correlated, others are negatively correlated. Thus, part of this unsystematic risk will cancel each other to certain extent. How each of these stocks are correlated is described by their variance and covariance matrix. Variance and covariance matrix measure how two different stocks move relative to each other in a period. 
Therefore, the covariance between two assets' return can be describe

as:

$$
\operatorname{Cov}(X, Y)=\frac{\sum_{t}\left(x_{t}-\bar{x}\right)\left(y_{t}-\bar{y}\right)}{T}
$$

Where:

$\mathrm{X}$ : denote asset $\mathrm{X}$ 's return

$Y$ : denote asset y's return

$\mathrm{T}$ : number of sampling periods

However, covariance is not something that could be directly interpreted. Thus, the correlation coefficient also needs to be calculated as follow:

$$
\operatorname{Corell}(X, Y)=\frac{\operatorname{Cov}(X, Y)}{\sigma_{x} \sigma_{y}}
$$

Where:

$\sigma=$ the standard deviation

The expected return of a portfolio, in the simplest form, is actually the mean or average of the stock's historical return.

$$
E\left(R_{p}\right)=\sum_{i=1}^{n} W_{i} E\left(R_{i}\right)
$$

The ex post variance and covariance data will be based on pricing data from 2004 onward. This will give minimum of 2 years monthly price data for the stock population.

Next, a risk is measure as the standard deviation of the portfolio. 


$$
\sigma_{p}=\sqrt{\sum_{i=1}^{n} \sum_{i=1}^{n} x_{i} X_{j} \sigma_{i j}}
$$

Although in general the higher risk stocks will have higher returns, a good portfolio should have higher return per unit risk. This parameter is named the Sharpe ratio, which can be written as follow:

$$
\theta=\frac{E\left(r_{x}\right)-C}{\sigma_{p}}
$$

Therefore, the optimization's goal is to maximize the Sharpe ratio given the selected stocks. The output of this process is the weight of particular stock in the portfolio.

The optimization process will be as follow:

$$
M A X \theta=\frac{E\left(r_{x}\right)-C}{\sigma_{p}}
$$

Where:

$$
\begin{gathered}
E\left(r_{x}\right)=\sum_{i}^{n} x_{i} E\left(r_{i}\right) \\
\sigma_{p}=\sqrt{\sum_{i=1}^{n} \sum_{i=1}^{n} x_{i} x_{j} \sigma_{i j}}
\end{gathered}
$$

Where:

$\theta=$ Sharpe ratio

$\mathrm{C}=3 \%$, implying $12 \%$ p.a, $7 \%$ risk free and $5 \%$ equity premium

$\mathrm{X}_{\mathrm{i}}=$ weight of the stock $\mathrm{i}$ in the portfolio

$\sigma_{\mathrm{p}}=$ standard deviation of the portfolio

$\sigma_{\mathrm{ij}}=$ co-variance between stock $\mathrm{i}$ and stock $\mathrm{j}$

The optimization will also be a subject to additional constraints:

a. No short selling or non-negative weighting. 
b. Maximum weighting for the individual stock is arbitrarily set at $20 \%$ of the portfolio to ensure enough diversification

Information ratio (IR) is the measurement on how worth it is to take active management. It is a ratio of alpha to its variance. Portfolio information ratio is equal to the weighted average of individual information ratio. If IR is zero, then we would better off to take passive management, because there is no additional excess return for overweighting and underweighting particular stock.

$$
I R=\frac{\operatorname{mean}\left(Y_{n}-X_{n}\right)}{\sigma_{\left(Y_{n}-X_{n}\right)}}
$$

Where:

$\mathrm{Y}_{\mathrm{n}}=$ portfolio's return

$\mathrm{X}_{\mathrm{n}}=$ benchmark's return

The numerical process will be conducted in Excel platform. The variance and covariance matrix will be based on ex post data of monthly stock price in the last two year prior to the calculated period.

According to Wilder Jr (1978), there are two major problems in using momentum line trading principles. One is an erratic movement due to drastic changes in the price which will cause abrupt changes in momentum line. Thus, some smoothing is needed for this. The second problem is that it needs a constant base as a benchmark. Following wilder Jr (1978), this research also uses Relative Strength Index (RSI) to minimize the problems.

RSI can be written as follows:

$$
R S I=100-\frac{100}{R S}
$$


Where:

$$
R S=\frac{\text { Average_of }{ }_{-} x_{-} \text {days_up_closes }}{\text { Average_of _ } \text { _d_days_down_closes }_{-}}
$$

The RSI is interpreted as follow. The RSI index value is between of 0 100. The index above 70 shows that the stock has been overbought during the periods. Meanwhile, the value below 30 means that the stock has been oversold during the periods. There is also term called "failure swings". The divergence between the price movement and the RSI in above 70 and below 30 ranges is a strong indication of reversal.

The research variables used and the measures are summarized in the next table.

Table 2 - The Variables Measures

\begin{tabular}{|c|l|l|}
\hline No. & \multicolumn{1}{|c|}{ Conceptual Variables } & \multicolumn{1}{|c|}{ Measures } \\
\hline $\mathbf{1}$ & Quarterly Revenue & 4 qtrs geometric growth \\
\hline $\mathbf{2}$ & Quarterly Operating Income & 4 qtrs geometric growth \\
\hline $\mathbf{3}$ & Profitability & ROE \\
\hline $\mathbf{4}$ & Technical & 30D RSI \\
\hline $\mathbf{5}$ & $\begin{array}{l}\text { Price on 25-30 days after } \\
\text { ended quarter }\end{array}$ & 4 qtrs changes \\
\hline $\mathbf{6}$ & $\begin{array}{l}\text { Stock population index on 25- } \\
\text { 30 days } \\
\text { after ended quarter }\end{array}$ & qtrs changes \\
\hline
\end{tabular}

\section{Hypothesis testing procedure}

The research method used here is a simulation. It assumes that the purchase and selling date will be at one month after the end of quarters. The weighting will be rebalanced for every quarter and multiplied by the respective portfolio size.

Then it will compare the portfolio performance to the market capitalization weighted stock population index. The excess return due to active management based on momentum strategy will be measured from this comparison. 
The return is calculated as follow:

$$
\text { indexlevel }=\frac{\sum_{i=1}^{n} P_{i t} Q_{i t}}{\sum_{i=1}^{n} P_{i 1} Q_{i 1}} \bullet 100
$$

Where:

$\mathrm{P}_{\mathrm{it}}=$ price of stock $\mathrm{i}$ at period $\mathrm{t}$.

$\mathrm{Q}_{\mathrm{it}}=$ number of shares outstanding of stock $\mathrm{i}$ at period $\mathrm{t}$

Both geometric and arithmetic return will be calculated. For the arithmetic market return $R_{m}$ at period $t$ is defined as follow:

$$
R_{m t}=\left(\frac{\text { indexlevel }_{t}}{\text { indexlevel }_{t-1}}\right)-1
$$

Meanwhile, portfolio return $\mathrm{R}_{\mathrm{m}}$ at period $\mathrm{t}$ is defined as follow:

$$
R_{p t}=\left(\frac{\text { portofolio }_{t}}{\text { portofolio }_{t-1}}\right)-1
$$

For quarterly geometric return will be calculated as follow:

$$
R_{m t}=\sqrt[4]{\left(\text { indexlevel }_{t}\right)^{\left(\frac{1}{0.25^{*}}\right)}}
$$

Meanwhile, portfolio return $\mathrm{R}_{\mathrm{m}}$ at period $\mathrm{t}$ is defined as follow:

$$
R_{p t}=\sqrt[4]{\left(\text { portfolio }_{t}\right)^{\left(\frac{1}{0.25^{*} t}\right)}}
$$

This research hypothesizes that applying investing momentum style using revenue growth, operating growth, RSI and with consideration of ROE as the factor selection will beat the index of stock population performance. 
Then, the working hypothesis could be expressed as:

- $\quad$ Ho : $\mathrm{R}$ portfolio- $\mathrm{R}$ market $\leq 0$

- $\quad \mathrm{H} 1: \mathrm{R}$ portfolio- $\mathrm{R}$ market $>0$

The hypothesis testing will be applied on both arithmetic and geometric return. Both arguments can provide different informations. The geometric return will show an absolute return from the initial point, while the arithmetic return will inform about changes characteristic from one period to another.

Considering possibility of non normal distribution, the hypothesis will be tested with both T test and Mann-Whitney U test. Mann Whitney is non parametric test that require no normality assumption. Mann Whitney (MW) test is not superior than t-test, it only treat data differently.

MW test do not use the data itself but rather the rank of the data so doesn't require normal distribution assumption. However, it also causes the MW test to have weaker explanation power because not all information that is contained in the data is used.

In contrary, $T$ test use the data itself to do the test, thus it use all the information contained in the data-hence have higher explanation power. Nonetheless, it requires assumption that the sample is part of normally distributed data. This perquisite condition make $\mathrm{T}$ test less versatile than MW test for small and scattered sample.

The analysis is conducted through 14 steps which can be seen in Figure 2 below: 


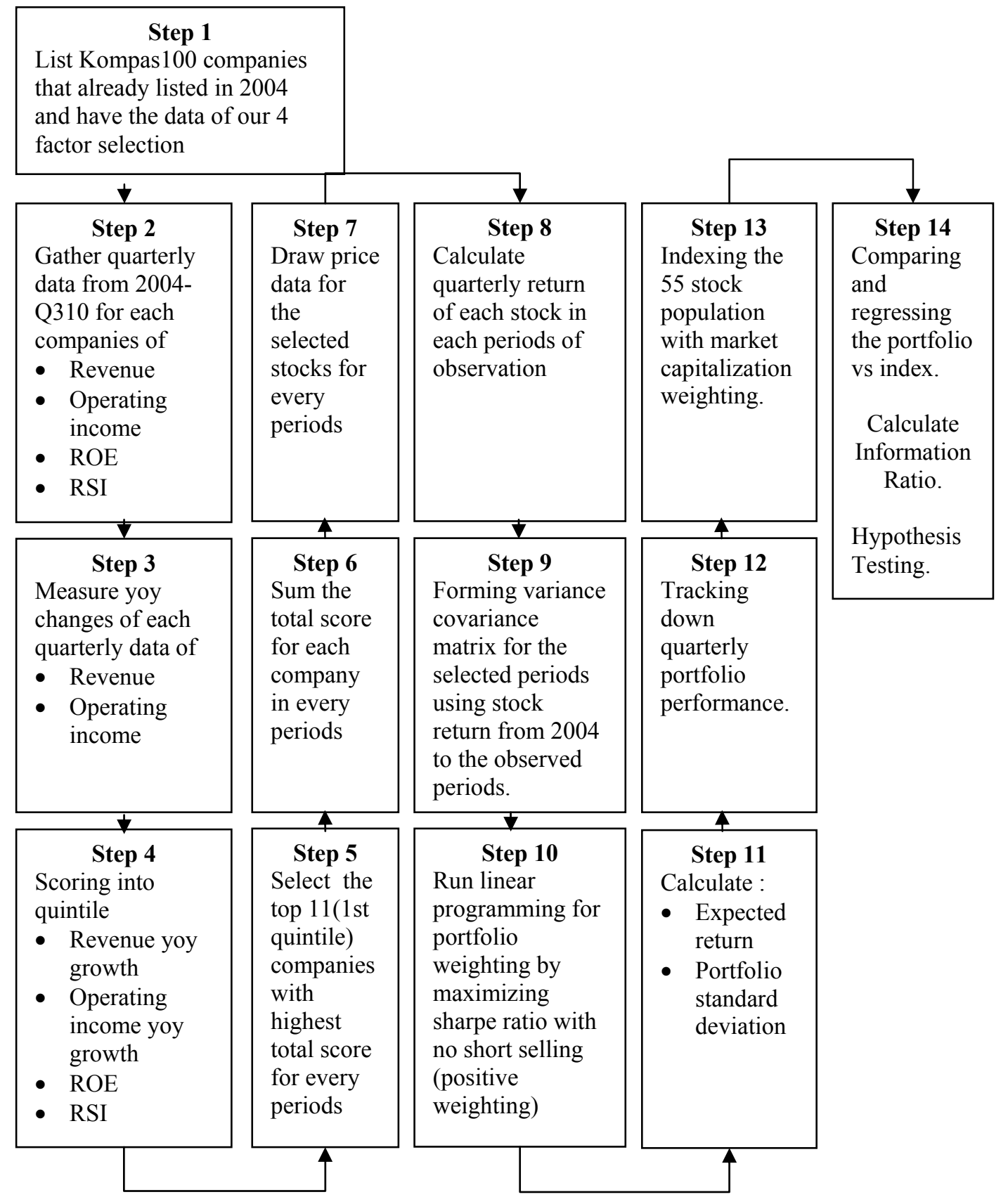

Figure 2. Process Flow Chart 


\section{RESULTS AND DISCUSSION}

\section{Stock Selection}

The following table 4 to table 7 are the descriptive statistic of the selection factor from the stock population. These following tables will also give a bit of background of Indonesia market dynamic. It show Indonesia's strong economic growth in sales growth, wide variation in managing operating income among the companies, level of profitability (ROE) and how these variables changes through the 2008 crisis.

Table 3. Sample Revenue Growth (\%)

\begin{tabular}{|c|c|c|c|}
\hline Period & Mean & Median & Standard Deviation \\
\hline Q106 & $29 \%$ & $14 \%$ & $56 \%$ \\
\hline Q206 & $42 \%$ & $18 \%$ & $166 \%$ \\
\hline Q306 & $23 \%$ & $15 \%$ & $45 \%$ \\
\hline Q406 & $20 \%$ & $12 \%$ & $56 \%$ \\
\hline Q107 & $24 \%$ & $13 \%$ & $53 \%$ \\
\hline Q207 & $27 \%$ & $19 \%$ & $44 \%$ \\
\hline Q307 & $25 \%$ & $21 \%$ & $32 \%$ \\
\hline Q407 & $41 \%$ & $28 \%$ & $49 \%$ \\
\hline Q108 & $33 \%$ & $22 \%$ & $43 \%$ \\
\hline Q208 & $37 \%$ & $28 \%$ & $45 \%$ \\
\hline Q308 & $30 \%$ & $26 \%$ & $37 \%$ \\
\hline Q408 & $15 \%$ & $18 \%$ & $39 \%$ \\
\hline Q109 & $6 \%$ & $7 \%$ & $32 \%$ \\
\hline Q209 & $-1 \%$ & $2 \%$ & $27 \%$ \\
\hline Q309 & $6 \%$ & $-1 \%$ & $57 \%$ \\
\hline Q409 & $10 \%$ & $9 \%$ & $28 \%$ \\
\hline Q110 & $17 \%$ & $13 \%$ & $29 \%$ \\
\hline Q210 & $17 \%$ & $9 \%$ & $30 \%$ \\
\hline
\end{tabular}

From table 3, above all 55 companies have average revenue growth of above 20\% since Q106 until Q308. Since Q106, Indonesia has strong double digits growth in revenue showing high economic growth, meanwhile there is a three quarters lag from the first subprime mortgage crisis burst in Q208. It was only in Q209 that the overall 
market have average negative growth in revenue. The crisis impacts on slowing down global demand of goods, service and commodity, which also impacts Indonesia economic.

Table 4 presents the operating income growth's descriptive statistic of all samples from Q106 to Q210. Operating income data is more volatile from revenue. It happens because in terms of operating income level, company execution and efficiency difference come to effect rather than systematic risk.

Table 4. Sample Operating Income Growth (\%)

\begin{tabular}{|c|c|c|c|}
\hline Period & Mean & Median & Standard Deviation \\
\hline Q106 & $12 \%$ & $1 \%$ & $116 \%$ \\
\hline Q206 & $230 \%$ & $2 \%$ & $1601 \%$ \\
\hline Q306 & $-5 \%$ & $7 \%$ & $177 \%$ \\
\hline Q406 & $114 \%$ & $-2 \%$ & $523 \%$ \\
\hline Q107 & $39 \%$ & $11 \%$ & $329 \%$ \\
\hline Q207 & $86 \%$ & $31 \%$ & $497 \%$ \\
\hline Q307 & $57 \%$ & $27 \%$ & $216 \%$ \\
\hline Q407 & $86 \%$ & $67 \%$ & $305 \%$ \\
\hline Q108 & $84 \%$ & $35 \%$ & $403 \%$ \\
\hline Q208 & $53 \%$ & $25 \%$ & $138 \%$ \\
\hline Q308 & $39 \%$ & $22 \%$ & $149 \%$ \\
\hline Q408 & $11 \%$ & $-7 \%$ & $120 \%$ \\
\hline Q109 & $-7 \%$ & $-8 \%$ & $70 \%$ \\
\hline Q209 & $-7 \%$ & $-4 \%$ & $56 \%$ \\
\hline Q309 & $32 \%$ & $4 \%$ & $170 \%$ \\
\hline Q409 & $66 \%$ & $4 \%$ & $376 \%$ \\
\hline Q110 & $79 \%$ & $25 \%$ & $343 \%$ \\
\hline Q210 & $13 \%$ & $21 \%$ & $206 \%$ \\
\hline
\end{tabular}

Table 5 presents ROE's descriptive statistic of all sample from Q106 to Q210. In term of profitability, ROE, post crisis recovery the average ROE level have not been back yet to $19 \%$ in Q106. In Q408$\mathrm{Q} 409$, the standard deviation jump to $44 \%, 39 \%, 50 \%, 48 \%$. It show that during the crisis the performance difference between good company and bad company increase. In the good time, bad company can have similar ROE with well managed company with higher degree of leverage, but this kind of business model will go bust in 
time of crisis.

Table 5. Sample ROE (\%)

\begin{tabular}{|c|c|c|c|}
\hline Period & Mean & Median & Standard Deviation \\
\hline Q106 & $19.3 \%$ & $15.5 \%$ & $15.3 \%$ \\
\hline Q206 & $19.1 \%$ & $15.3 \%$ & $16.7 \%$ \\
\hline Q306 & $19.1 \%$ & $15.3 \%$ & $18.8 \%$ \\
\hline Q406 & $18.1 \%$ & $14.7 \%$ & $18.6 \%$ \\
\hline Q107 & $16.8 \%$ & $12.8 \%$ & $19.1 \%$ \\
\hline Q207 & $21.2 \%$ & $14.8 \%$ & $25.5 \%$ \\
\hline Q307 & $21.2 \%$ & $13.4 \%$ & $24.4 \%$ \\
\hline Q407 & $22.1 \%$ & $14.8 \%$ & $22.0 \%$ \\
\hline Q108 & $23.1 \%$ & $17.2 \%$ & $20.4 \%$ \\
\hline Q208 & $23.2 \%$ & $19.2 \%$ & $17.8 \%$ \\
\hline Q308 & $22.8 \%$ & $20.6 \%$ & $16.3 \%$ \\
\hline Q408 & $11.4 \%$ & $12.7 \%$ & $43.9 \%$ \\
\hline Q109 & $8.4 \%$ & $10.2 \%$ & $39.1 \%$ \\
\hline Q209 & $7.6 \%$ & $9.8 \%$ & $49.5 \%$ \\
\hline Q309 & $7.2 \%$ & $8.5 \%$ & $48.2 \%$ \\
\hline Q409 & $15.6 \%$ & $12.3 \%$ & $26.1 \%$ \\
\hline Q110 & $18.3 \%$ & $15.0 \%$ & $22.2 \%$ \\
\hline Q210 & $17.3 \%$ & $13.7 \%$ & $23.1 \%$ \\
\hline
\end{tabular}

From table 6 presents RSI's descriptive statistic of all sample from Q106 to Q210.RSI data show from Q106-Q210 the average RSI is between 38-69. This mean that there is a trading cycle among these stocks. Meaning that it have never being overbought altogether, there is always leading and laggard stock in this population. That is why on average basis there is no period that the population are all oversold $(<30)$ nor overbought $(>70)$. Thus the opportunity to find laggard stock is always exist.

Table 6. Sample RSI 30D

\begin{tabular}{|c|c|c|c|}
\hline Period & Mean & Median & Standard Deviation \\
\hline Q106 & 57.4 & 56.0 & 9.3 \\
\hline Q206 & 38.3 & 38.0 & 6.2 \\
\hline Q306 & 54.8 & 56.0 & 11.4 \\
\hline
\end{tabular}




\begin{tabular}{|l|c|c|c|}
\hline Q406 & 56.2 & 57.0 & 11.0 \\
\hline Q107 & 48.6 & 48.0 & 10.1 \\
\hline Q207 & 55.3 & 58.0 & 12.5 \\
\hline Q307 & 68.9 & 69.0 & 7.0 \\
\hline Q407 & 48.5 & 49.0 & 9.2 \\
\hline Q108 & 44.0 & 45.0 & 10.4 \\
\hline Q208 & 44.9 & 45.0 & 13.1 \\
\hline Q308 & 42.6 & 41.0 & 9.4 \\
\hline Q408 & 44.5 & 47.0 & 13.7 \\
\hline Q109 & 53.0 & 54.0 & 9.8 \\
\hline Q209 & 55.4 & 56.0 & 8.2 \\
\hline Q309 & 52.6 & 52.0 & 7.7 \\
\hline Q409 & 51.7 & 52.0 & 10.5 \\
\hline Q110 & 60.3 & 61.0 & 10.2 \\
\hline Q210 & 48.7 & 48.0 & 9.2 \\
\hline
\end{tabular}

Table 7 is a compilation of buy listed for each quarter. They are the eleven highest scored from the population in each period. However, the stock name order does not reflect preference.

Table 7. Chosen Portfolio in Each Period

\begin{tabular}{|c|c|c|c|c|c|c|c|c|}
\hline Q106 & Q206 & Q306 & Q406 & Q107 & Q207 & Q307 & Q407 & Q108 \\
\hline PGAS & CTRA & UNSP & ANTM & JPFA & ANTM & ANTM & LSIP & LSIP \\
\hline BLTA & UNSP & PGAS & BLTA & ASGR & INCO & AALI & BMTR & TBLA \\
\hline CTRA & CTRS & PTBA & INCO & MTDL & AALI & RALS & UNTR & AALI \\
\hline UNVR & ANTM & INCO & BNGA & ANTM & TINS & TINS & AALI & UNSP \\
\hline AALI & PGAS & ANTM & ASGR & INCO & BMTR & MTDL & ANTM & BLTA \\
\hline TLKM & BUMI & BBRI & UNSP & TINS & ASGR & INCO & TINS & JPFA \\
\hline UNTR & CPIN & BNBR & BBRI & PTBA & ASII & ASII & UNSP & CPIN \\
\hline SMGR & ELTY & BNGA & JPFA & BUMI & UNSP & LSIP & SMGR & INDF \\
\hline KLBF & BNBR & JPFA & CPIN & ELTY & SMRA & TLKM & SMRA & SMCB \\
\hline UNSP & SMRA & TBLA & KLBF & AALI & LSIP & UNTR & BNGA & UNTR \\
\hline ASGR & PNLF & CPIN & PGAS & INDF & JPFA & INKP & TLKM & BNBR \\
\hline Q208 & Q308 & Q408 & Q109 & Q209 & Q309 & Q409 & Q110 & Q210 \\
\hline BLTA & BLTA & BUMI & PTBA & PTBA & PGAS & SMCB & MYOR & INCO \\
\hline
\end{tabular}




\begin{tabular}{|l|l|l|l|l|l|l|l|l|}
\hline Q208 & Q308 & Q408 & Q109 & Q209 & Q309 & Q409 & Q110 & Q210 \\
\hline UNTR & BUMI & BLTA & BBRI & ASGR & ASGR & INCO & AALI & ANTM \\
SMGR & PTBA & JPFA & BUMI & BNGA & TLKM & GJTL & GJTL & GJTL \\
CPIN & BNGA & MYOR & JPFA & SMGR & JPFA & AALI & INTP & KIJA \\
INDF & SMCB & PTBA & KLBF & BBCA & TSPC & CPIN & TSPC & PNBN \\
BNBR & KIJA & ASGR & UNVR & CPIN & KLBF & UNTR & TLKM & MTDL \\
INTP & JPFA & KLBF & MYOR & LPKR & UNVR & PGAS & CMNP & BNBR \\
ASII & MEDC & BMRI & SMCB & BBRI & AALI & TSPC & KIJA & BUMI \\
PTBA & ASII & SMCB & UNTR & UNTR & TBLA & KLBF & INCO & CMNP \\
PGAS & UNSP & UNTR & SMGR & PGAS & SMGR & UNVR & UNVR & ELTY \\
LSIP & UNTR & SMGR & PGAS & BMRI & BBRI & SMGR & SMGR & LSIP \\
\hline
\end{tabular}

Displayed data on Table 8 below is the result of linear programming optimization. As expected, linear optimization tends to polarized toward the winners, where $20 \%$ and $1 \%$ weighting dominate the populated table. The optimization constraint include limit of maximum weighting of $20 \%$ and minimum weighting of $1 \%$. This constraint effectively to maintain the number of stocks in the buy list stay 11 stocks.

Table 8 - Portfolio Weighting

\begin{tabular}{|l|c|l|c|l|c|l|c|l|c|}
\hline Q106 & wgt & Q206 & wgt & Q306 & wgt & Q406 & wgt & Q107 & wgt \\
\hline PGAS & $20 \%$ & CTRA & $1 \%$ & UNSP & $20 \%$ & ANTM & $16 \%$ & PGAS & $16 \%$ \\
BLTA & $20 \%$ & UNSP & $20 \%$ & PGAS & $20 \%$ & BLTA & $18 \%$ & BLTA & $18 \%$ \\
CTRA & $1 \%$ & CTRS & $1 \%$ & PTBA & $6 \%$ & INCO & $20 \%$ & CTRA & $20 \%$ \\
UNVR & $1 \%$ & ANTM & $20 \%$ & INCO & $20 \%$ & BNGA & $1 \%$ & UNVR & $1 \%$ \\
AALI & $20 \%$ & PGAS & $20 \%$ & ANTM & $20 \%$ & ASGR & $1 \%$ & AALI & $1 \%$ \\
TLKM & $1 \%$ & BUMI & $20 \%$ & BBRI & $9 \%$ & UNSP & $20 \%$ & TLKM & $20 \%$ \\
UNTR & $20 \%$ & CPIN & $14 \%$ & BNBR & $1 \%$ & BBRI & $1 \%$ & UNTR & $1 \%$ \\
SMGR & $1 \%$ & ELTY & $1 \%$ & BNGA & $1 \%$ & JPFA & $1 \%$ & SMGR & $1 \%$ \\
KLBF & $1 \%$ & BNBR & $1 \%$ & JPFA & $1 \%$ & CPIN & $1 \%$ & KLBF & $1 \%$ \\
UNSP & $14 \%$ & SMRA & $1 \%$ & TBLA & $1 \%$ & KLBF & $1 \%$ & UNSP & $1 \%$ \\
ASGR & $1 \%$ & PNLF & $1 \%$ & CPIN & $1 \%$ & PGAS & $19 \%$ & ASGR & $19 \%$ \\
\hline
\end{tabular}

\begin{tabular}{|l|c|l|l|l|l|l|l|l|l|}
\hline Q207 & wgt & Q307 & wgt & Q407 & wgt & Q108 & wgt & Q208 & wgt \\
\hline ANTM & $16 \%$ & ANTM & $16 \%$ & LSIP & $16 \%$ & LSIP & $16 \%$ & BLTA & $16 \%$ \\
INCO & $18 \%$ & AALI & $18 \%$ & BMTR & $18 \%$ & TBLA & $18 \%$ & UNTR & $18 \%$ \\
AALI & $20 \%$ & RALS & $20 \%$ & UNTR & $20 \%$ & AALI & $20 \%$ & SMGR & $20 \%$ \\
\hline
\end{tabular}




\begin{tabular}{|l|c|l|c|l|c|l|c|l|c|}
\hline Q207 & wgt & Q307 & wgt & Q407 & wgt & Q108 & wgt & Q208 & wgt \\
\hline TINS & $1 \%$ & TINS & $1 \%$ & AALI & $1 \%$ & UNSP & $1 \%$ & CPIN & $1 \%$ \\
BMTR & $1 \%$ & MTDL & $1 \%$ & ANTM & $1 \%$ & BLTA & $1 \%$ & INDF & $1 \%$ \\
ASGR & $20 \%$ & INCO & $20 \%$ & TINS & $20 \%$ & JPFA & $20 \%$ & BNBR & $20 \%$ \\
ASII & $1 \%$ & ASII & $1 \%$ & UNSP & $1 \%$ & CPIN & $1 \%$ & INTP & $1 \%$ \\
UNSP & $1 \%$ & LSIP & $1 \%$ & SMGR & $1 \%$ & INDF & $1 \%$ & ASII & $1 \%$ \\
SMRA & $1 \%$ & TLKM & $1 \%$ & SMRA & $1 \%$ & SMCB & $1 \%$ & PTBA & $1 \%$ \\
LSIP & $1 \%$ & UNTR & $1 \%$ & BNGA & $1 \%$ & UNTR & $1 \%$ & PGAS & $1 \%$ \\
JPFA & $19 \%$ & INKP & $19 \%$ & TLKM & $19 \%$ & BNBR & $19 \%$ & LSIP & $19 \%$ \\
\hline
\end{tabular}

\begin{tabular}{|l|c|c|c|l|c|l|c|l|c|}
\hline Q308 & wgt & Q408 & wgt & Q109 & wgt & Q209 & wgt & Q309 & wgt \\
\hline BLTA & $16 \%$ & BUMI & $16 \%$ & PTBA & $16 \%$ & PTBA & $16 \%$ & PGAS & $16 \%$ \\
BUMI & $18 \%$ & BLTA & $18 \%$ & BBRI & $18 \%$ & ASGR & $18 \%$ & ASGR & $18 \%$ \\
PTBA & $20 \%$ & JPFA & $20 \%$ & BUMI & $20 \%$ & BNGA & $20 \%$ & TLKM & $20 \%$ \\
BNGA & $1 \%$ & MYOR & $1 \%$ & JPFA & $1 \%$ & SMGR & $1 \%$ & JPFA & $1 \%$ \\
SMCB & $1 \%$ & PTBA & $1 \%$ & KLBF & $1 \%$ & BBCA & $1 \%$ & TSPC & $1 \%$ \\
KIJA & $20 \%$ & ASGR & $20 \%$ & UNVR & $20 \%$ & CPIN & $20 \%$ & KLBF & $20 \%$ \\
JPFA & $1 \%$ & KLBF & $1 \%$ & MYOR & $1 \%$ & LPKR & $1 \%$ & UNVR & $1 \%$ \\
MEDC & $1 \%$ & BMRI & $1 \%$ & SMCB & $1 \%$ & BBRI & $1 \%$ & AALI & $1 \%$ \\
ASII & $1 \%$ & SMCB & $1 \%$ & UNTR & $1 \%$ & UNTR & $1 \%$ & TBLA & $1 \%$ \\
UNSP & $1 \%$ & UNTR & $1 \%$ & SMGR & $1 \%$ & PGAS & $1 \%$ & SMGR & $1 \%$ \\
UNTR & $19 \%$ & SMGR & $19 \%$ & PGAS & $19 \%$ & BMRI & $19 \%$ & BBRI & $19 \%$ \\
\hline
\end{tabular}

\begin{tabular}{|l|c|l|c|l|c|}
\hline Q409 & wgt & Q110 & wgt & Q210 & wgt \\
& & & & & \\
\hline PGAS & $1 \%$ & MYOR & $1 \%$ & INCO & $20 \%$ \\
BLTA & $20 \%$ & AALI & $20 \%$ & ANTM & $20 \%$ \\
CTRA & $1 \%$ & GJTL & $1 \%$ & GJTL & $1 \%$ \\
UNVR & $20 \%$ & INTP & $1 \%$ & KIJA & $14 \%$ \\
AALI & $1 \%$ & TSPC & $1 \%$ & PNBN & $1 \%$ \\
TLKM & $20 \%$ & TLKM & $20 \%$ & MTDL & $1 \%$ \\
UNTR & $20 \%$ & CMNP & $4 \%$ & BNBR & $1 \%$ \\
SMGR & $1 \%$ & KIJA & $12 \%$ & BUMI & $20 \%$ \\
KLBF & $14 \%$ & INCO & $20 \%$ & CMNP & $1 \%$ \\
UNSP & $1 \%$ & UNVR & $1 \%$ & ELTY & $1 \%$ \\
ASGR & $1 \%$ & SMGR & $18 \%$ & LSIP & $20 \%$ \\
\hline
\end{tabular}

\section{Portfolio Performance Analysis}

The performance analysis start with (1) comparing the realized return and realized sharpe ratio with the predicted result from Markowitz 
optimization. Then it will continue with (2) comparison the portfolio performance to the benchmark. Last but not least, (3) the outperformance will be statistically tested with $t$ statistic to see its level of significance.

\section{Result on Return}

As presented in Figure 3 below, realized porttfolio return is higher than expected return. The realized return has average geometric return of 35.6\%/year over Q106-Q2110 periods while the expected return only has $2.3 \%$ return. Realized return also has much higher volatility. The realized return has $26.8 \%$ standard deviattion while the expected return only $3.9 \%$.

Expected return that calculated by Markowitz method is based on historical variance and covariance of the buy listed stock for every periods. It is not agile enough to accurately predict the return at a very volatile market. Only if the market is trending for longer period of time that Markowitz calculated expected return can have better accuracy.

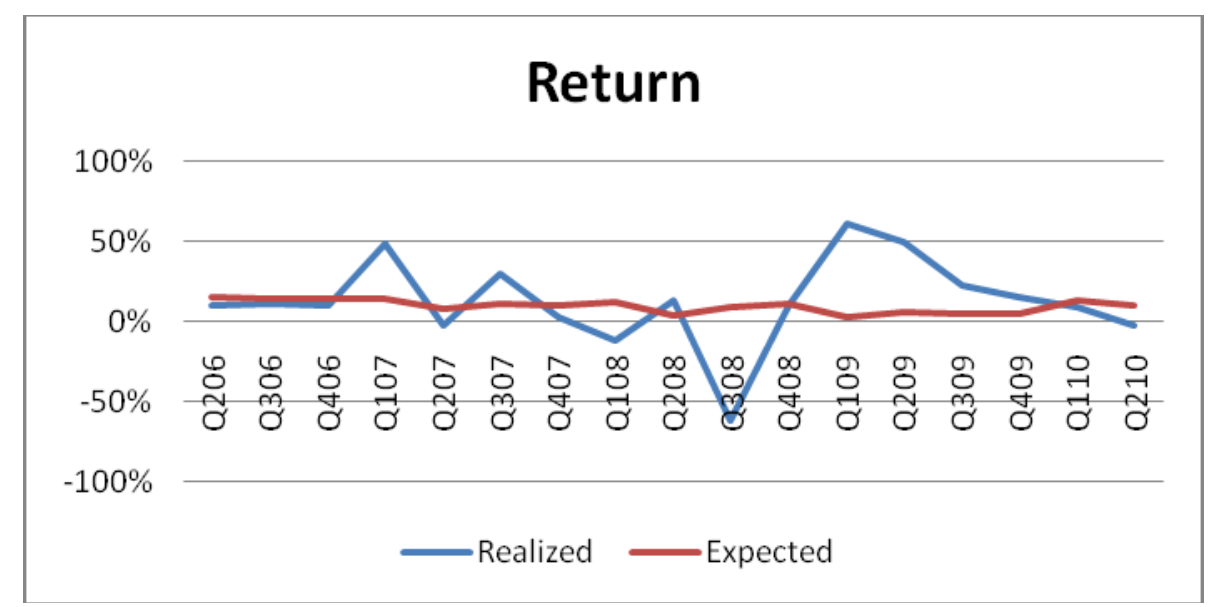

Figure 3. Realized Versus Expected Return

\section{Result on Sharpe Ratio}

Realized sharpe ratio also much more volatile with $145 \%$ standard deviation compare to the expected sharpe ratio of only $20 \%$ (Figure 4 ). However visual observation of normalized sharpe ratio(dividing 
with the largest value) still moving with the same trend except for period of Q408-Q309 where the realized performance rcovered faster than the expected value. So the calculated sharp ratio can give sense of direction but not a magnitude.

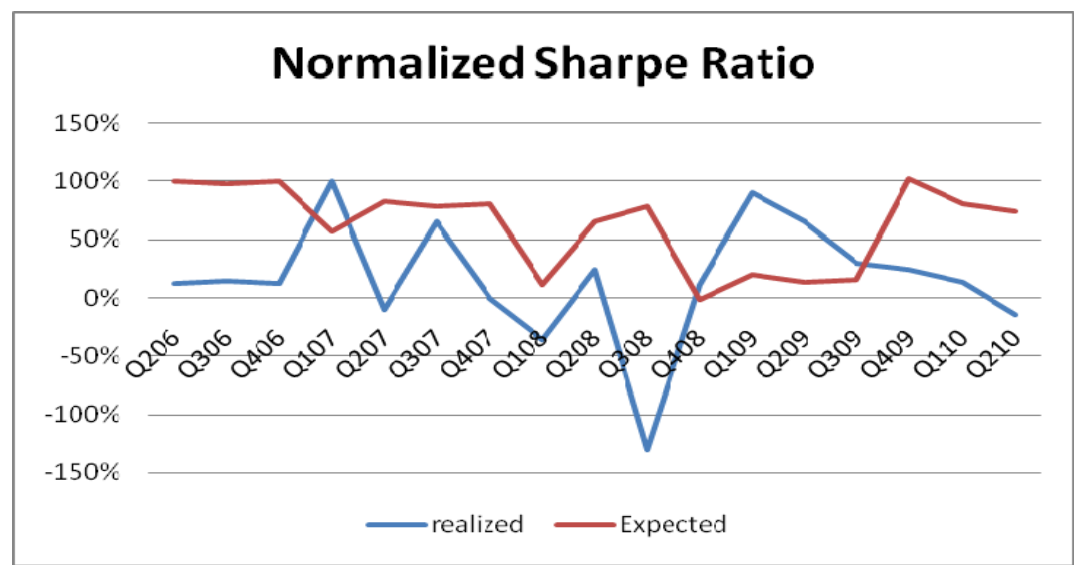

Figure 4. Realized Versus Expected Sharpe Ratio

Based on visual observation, the momentum strategized portfolio outperformance happens mostly on upward trending market from Q406-Q208 and Q109-Q110. On the downturn, it post higher losses, however with previous gain on the upward trending market its index value still at the level with benchmark (Figure 5)

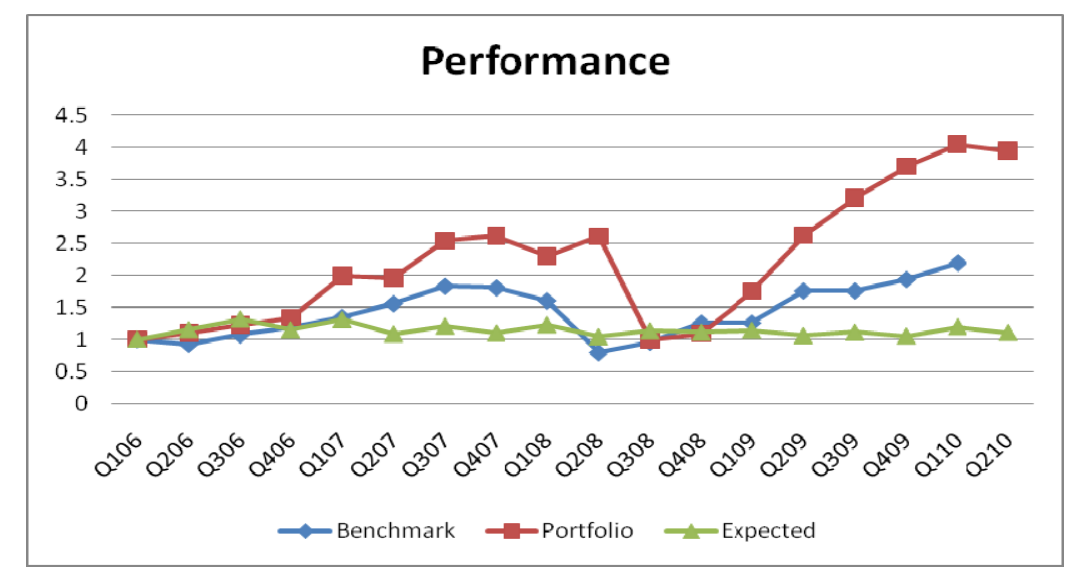

Figure 5. Portfolio Performance Comparison 
Alpha is the indicator of outperformance. For arithmetic return, as shown in Table 9 below, the alpha is $2.65 \%$ per quarter. The p-value is 0.55 , implying that the arithmetic return alpha is not signicant. However, if the geometric return is regressed it shows statistically significant alpha of $6.5 \%$ with p-value of 0.000127 , hence statistically significant, as shown in table 10.

Table 9. Regression Result of Portfolio Arithmetic Return Versus Benchmark

\begin{tabular}{|l|c|c|c|}
\hline & Coefficients & t Stat & p-value \\
\hline Alpha & 0.026508 & 0.617174 & 0.546375 \\
\hline Beta & 1.111190 & 5.650906 & $4.61 \mathrm{E}-05$ \\
\hline R Square & 0.68039 & - & - \\
\hline F & 31.93273 & - & 0.00004 \\
\hline
\end{tabular}

Table 10. Regression Result of Portfolio Geometric Return Versus Benchmark

\begin{tabular}{|l|c|c|c|c|}
\hline & Coefficients & $\begin{array}{c}\text { Standard } \\
\text { Error }\end{array}$ & t Stat & P-value \\
\hline Alpha & 0.065081 & 0.012723 & 5.115431 & 0.000127 \\
\hline Beta & 0.762815 & 0.209247 & 3.645523 & 0.002392 \\
\hline R Square & 0.469774 & - & - & - \\
\hline F & 13.28984 & - & - & 0.002392 \\
\hline
\end{tabular}

The Beta is showing the correlation of the portfolio with the benchmark. Table 12 shows that beta based on arithmetic return is 1.1. This means that the portfolio is more volatile than the benchmark 
subject to higher return and risk. This beta is statistically significant with $\mathrm{P}$-value of $4.6 \times 10^{-5}$. Table 10 shows that the geometric return derived beta is 0.76 in value. This mean the geometric return of the portfolio is not more volatile than the benchmark. Based on p-value of 0.0024 , it is also statistically significant.

\section{Result on Information Ratio}

The information ratio calculations will give us guidance whether the strategy is worthwhile to be taken as active portfolio management strategy. Positive result would mean that the strategy is worthwhile to be taken as active portfolio management strategy. On arithmetic return, the information ratio is 0.231 while for geometric return the information ratio is 1.46 . Positive ratio for both return means that the strategy can be used as active portfolio strategy.

\section{HYPOTHESIS TESTING Result}

This research want to prove that the portfolio have statistically significant positive return above the benchmark return. There are four statistical testing result. For each of arithmetic return difference and geometric return difference there will be two statistical test, T-test and Mann-Whitney test. Mann-Whitney critical $U$ value is determined using table. This is due to small number of sample, 17 per arrays. Both testing will use 5\% significant level.

In table 11 and table 12, the return data of both benchmarks (Rm) and portfolio ( $\mathrm{Rp})$ are displayed with its respective rank. As it has been explained in the Research Design section, the rank data will be used to do Mann-Whitney test. The sum of the rank data can give us an intuitive hindsight how big is the difference between the two arrays. The bigger the sum of the rank of an array it give signal that its data are larger than the other array, however the $U$ value test still need to be done to determine how significant the difference between the two arrays.

Table 11. Hypothesis Testing on Arithmetical Return Difference

\begin{tabular}{|l|r|l|l|r|r|}
\hline & & & & \multicolumn{2}{|c|}{ Rank } \\
\cline { 5 - 7 } Period & Rp-Rm & Rm & Rp & Rm & \multicolumn{1}{c|}{ Rp } \\
\hline Q206 & $17 \%$ & $-8 \%$ & $10 \%$ & 30 & 21 \\
\hline Q306 & $-5 \%$ & $16 \%$ & $11 \%$ & 11 & 17 \\
\hline
\end{tabular}




\begin{tabular}{|l|r|r|r|r|r|}
\hline & & & & \multicolumn{2}{|c|}{ Rank } \\
\cline { 5 - 6 } Period & Rp-Rm & Rm & Rp & Rm & \multicolumn{1}{c|}{ Rp } \\
\hline Q406 & $-1 \%$ & $11 \%$ & $10 \%$ & 18 & 22 \\
\hline Q107 & $36 \%$ & $13 \%$ & $49 \%$ & 16 & 3 \\
\hline Q207 & $-18 \%$ & $16 \%$ & $-2 \%$ & 12 & 28 \\
\hline Q307 & $13 \%$ & $17 \%$ & $30 \%$ & 10 & 7 \\
\hline Q407 & $4 \%$ & $-1 \%$ & $3 \%$ & 26 & 24 \\
\hline Q108 & $-3 \%$ & $-10 \%$ & $-12 \%$ & 31 & 32 \\
\hline Q208 & $15 \%$ & $-2 \%$ & $14 \%$ & 27 & 14 \\
\hline Q308 & $-12 \%$ & $-50 \%$ & $-62 \%$ & 33 & 34 \\
\hline Q408 & $-10 \%$ & $20 \%$ & $10 \%$ & 9 & 19 \\
\hline Q109 & $29 \%$ & $32 \%$ & $61 \%$ & 6 & 1 \\
\hline Q209 & $14 \%$ & $36 \%$ & $50 \%$ & 4 & 2 \\
\hline Q309 & $-14 \%$ & $36 \%$ & $22 \%$ & 4 & 8 \\
\hline Q409 & $13 \%$ & $2 \%$ & $15 \%$ & 25 & 13 \\
\hline Q110 & $-1 \%$ & $10 \%$ & $9 \%$ & 20 & 23 \\
\hline Q210 & $-16 \%$ & $13 \%$ & $-3 \%$ & 15 & 29 \\
\hline \multicolumn{3}{|c|}{ Sum of the rank } & & 297 & 297 \\
\hline
\end{tabular}

Table 12. Geometric Return Data and Rank

\begin{tabular}{|c|c|c|c|c|c|}
\hline & & & & \multicolumn{2}{|c|}{ Rank } \\
\cline { 5 - 6 } Period & Rp-Rm & Rm & Rp & Rm & Rp \\
\hline Q206 & $17 \%$ & $-8 \%$ & $10 \%$ & 34 & 10 \\
\hline Q306 & $7 \%$ & $4 \%$ & $11 \%$ & 28 & 8 \\
\hline Q406 & $4 \%$ & $6 \%$ & $10 \%$ & 20 & 9 \\
\hline Q107 & $11 \%$ & $8 \%$ & $19 \%$ & 17 & 1 \\
\hline Q207 & $5 \%$ & $9 \%$ & $14 \%$ & 11 & 4 \\
\hline Q307 & $6 \%$ & $11 \%$ & $17 \%$ & 7 & 2 \\
\hline Q407 & $6 \%$ & $9 \%$ & $15 \%$ & 14 & 3 \\
\hline Q108 & $5 \%$ & $6 \%$ & $11 \%$ & 19 & 6 \\
\hline Q208 & $6 \%$ & $5 \%$ & $11 \%$ & 21 & 5 \\
\hline Q308 & $2 \%$ & $-2 \%$ & $0 \%$ & 33 & 31 \\
\hline
\end{tabular}




\begin{tabular}{|c|c|c|c|c|c|}
\hline & & & & \multicolumn{2}{|c|}{ Rank } \\
\cline { 5 - 6 } Period & Rp-Rm & Rm & Rp & Rm & Rp \\
\hline Q408 & $1 \%$ & $0 \%$ & $1 \%$ & 32 & 30 \\
\hline Q109 & $3 \%$ & $2 \%$ & $5 \%$ & 29 & 24 \\
\hline Q209 & $3 \%$ & $4 \%$ & $8 \%$ & 26 & 18 \\
\hline Q309 & $5 \%$ & $4 \%$ & $9 \%$ & 27 & 15 \\
\hline Q409 & $5 \%$ & $5 \%$ & $9 \%$ & 25 & 13 \\
\hline Q110 & $4 \%$ & $5 \%$ & $9 \%$ & 22 & 12 \\
\hline Q210 & $3 \%$ & $5 \%$ & $8 \%$ & 23 & 16 \\
\hline Sum of the rank & & & & 388 & 207 \\
\hline
\end{tabular}

For the arithmetic return difference, both testing accept $\mathrm{H}_{0}$. Thus, the portfolio could be said outperform the benchmark. The T-test hypothesis testing shows p-value of 0.17 , as shown in table 13 . The Mann-Whitney test hypothesis testing show that the portfolio return (Rp) is smaller than $\mathrm{U}$ critical, then $\mathrm{H}_{0}$ is accepted, as shown in table 14.

Table 13. Student $T$ Hypothesis Testing on Arithmetical Return Difference

\begin{tabular}{|l|c|}
\hline \multicolumn{1}{|c|}{ Null Hypothesis $\boldsymbol{\mu}<$} & $\mathbf{0 \%}$ \\
\hline Level of significance & 0.05 \\
\hline Sample size & 17 \\
\hline Sample mean & $4 \%$ \\
\hline Standard deviation & 0.157891732 \\
\hline Std error of the mean & 0.03829437 \\
\hline Degree of freedom & 16 \\
\hline T statistic & 0.953531571 \\
\hline p-value & 0.177252763 \\
\hline Information ratio & 0.231265376 \\
\hline
\end{tabular}


Table 14. Mann-Whitney Hypothesis Testing on Arithmetic Return Difference

\begin{tabular}{|l|r|}
\hline \multicolumn{1}{|c|}{ Measurement } & \multicolumn{1}{c|}{ Value } \\
\hline $\mathrm{n} \mathrm{Rm}$ & 17 \\
\hline $\mathrm{n} \mathrm{Rp}$ & 17 \\
\hline $\mathrm{u} \mathrm{Rm}$ & 145 \\
\hline $\mathrm{u} \mathrm{Rp}$ & 145 \\
\hline$(\mathrm{n} \mathrm{Rm})(\mathrm{n} \mathrm{Rp}) / 2$ & 144.5 \\
\hline $\mathrm{U}$ critical $(17,17,0.05)$ & 224 \\
\hline Conclusion & Accept $\mathrm{H}_{0}$ \\
\hline
\end{tabular}

For the geometric return difference, both testing reject $\mathrm{H}_{0}$. This means that on geometric basis, the portfolio outperform the benchmark. As shown in table $15, \mathrm{p}$-value from T-test is $9 \times 10^{-6}$, already in rejection region with $5 \%$ level of significant. On table 16 the $U$ critical value is also smaller than $U$ portfolio return $(\mathrm{Rp})$, thus it is also rejecting the $\mathrm{H}_{0}$.

Table 15. Student T Hypothesis Testing on Geometrical Return Difference

\begin{tabular}{|l|c|}
\hline Null Hypothesis $\boldsymbol{\mu}<$ & $\mathbf{0 \%}$ \\
\hline Level of significance & 0.05 \\
\hline Sample size & 17 \\
\hline Sample mean & $5 \%$ \\
\hline Standard deviation & 0.037660585 \\
\hline Std error of the mean & 0.009134033 \\
\hline Degree of freedom & 16 \\
\hline T statistic & 6.015929419 \\
\hline p-value & $8.98656 \mathrm{E}-06$ \\
\hline Information ratio & 1.459077202 \\
\hline
\end{tabular}


Table 16. Mann-Whitney Hypothesis Testing on Geometrical Return Difference

\begin{tabular}{|l|r|}
\hline Measurement & \multicolumn{1}{c|}{ Value } \\
\hline $\mathrm{n} \mathrm{Rm}$ & 17 \\
\hline $\mathrm{n} \mathrm{Rp}$ & 17 \\
\hline $\mathrm{u} \mathrm{Rm}$ & 54 \\
\hline $\mathrm{u} \mathrm{Rp}$ & 235 \\
\hline$(\mathrm{n} \mathrm{Rm})(\mathrm{n} \mathrm{Rp}) / 2$ & 144.5 \\
\hline $\mathrm{U}(17,17,0.05)$ & 224 \\
\hline Conclusion & Reject $\mathrm{H}_{0}$ \\
\hline
\end{tabular}

Although both result on arithmetic and geometric return seems contradicting, it is actually give hint of what investor can expect from using momentum investing strategy. Insignificant arithmetic returns outperformance of the portfolio explains that on quarter to quarter basis, the return of momentum strategy can be extreme in both directions. Significant geometric returns outperformance explains that, despite volatile return on quarter-to-quarter basis, if it is consistently applied, the momentum strategy can outperform the market.

The results imply that for longer term investors, the momentum investing strategy could be implemented in Indonesia market. This is apparent from significant positive geometric return above the benchmark for Q106-Q210. However in the short term, in quarter to quarter basis, it can be extremely outperform or underperform the market. This is shown by statistically insgnificant and higher standard deviation of positive arithmetic return above the benchmark.

Brokerage firm also can construct momentum investing index buy list and weighting. This would be a value added service to the client to provide them with investing ideas. Since the finding is that the momentum investing works better for longer term periods, concistency is the key to successfully use momentum strategy. In the event of the downturn, no one really can locate the reversal points thus to consistently stick to the strategy is important. 


\section{CONCLUSION AND FURTHER RESEARCH}

Based on the sample, there is an evidence with level of significant of 0.05 that the geometric return of the momentum investing portfolio outperform the benchmark, market weighted index of the population. Momentum investing outperformance is also a proof that during our periods of observation and within our sample space the market is not in weak-form efficiency. Therefore, it can be concluded that the momentum investing's perform better in upward trending market. This can be explained by increasing capital inflow in the bull market and these momentum stock become the preffered choices.

During the downturn, the portfolio underperformed the benchmark on quarter to quarter basis. This is what make the arithmetic outperformance of momentum investing is not significant because on the upward market the momentum investing is significantly outperform the market but in the downturn, it also significantly underperform the market.

But the gain from the bull market still keep the portfolio performance index is higher than the benchmark. It is also reflected in the quarterly geometric return, that the portfolio's is always higher than the benchmark's.

The existance of alpha in this study show indication that momentum investing can beat the market and can be an alternative of simple strategy that applicable to Indonesia market. But it to require consistency, meaning to stick with strategy even in the downturn because it perform best in capturing market recovery and have high outperformance, for example 29\% outperformance on Q109. Doing this startegy on and off will increase the risk of misphase the market i.e due to underperformance in downturn and we stop using the strategy then we will miss the recovery turn which can cover the downperformance to the market during the downturn.

This research can be improved by adjusting the portfolio for every company, where they release their financials. This will excalate the complexity of the research into real option problem. In adjusting portfolio every time when a company release a financials, there is a risks that the other company who has not published their financials yet 
is actually better buy than all the company that have released their financials result.

\section{REFERENCE}

Bazdan, Z, 2010. "Sell When The Violins Are Playing- Buy When The Cannons Rumble". Case Study: Technical Analysis and Chartist. Nase Gospodarstvo.

Beningga, S.2008. “Financial modeling”. MIT, Massachuset.

Bettman, J.L., Saults, S.J., Schultz, E.L. (2009). "Fundamental and Technical analysis : Substitute or Complements?'Accounting \& Finance, 21-26.

Bird, R. and Casavecchia,L., 2007.Value enhancement using momentum indicators: the European experience. School of Finance and Economics, University of Technology, Sydney, Australia.

Brinson,G.P, Singer,B.D. and Beebower,G.L. 1991 "Determinants of Portfolio Performance II: An Update," Financial Analysts Journal 47, no. 3 (May-June 1991): 40-48, Charloteville.

Brinson, G.P., L. Hood,R., and Beebower, G.L. 1986 “Determinants of Portfolio Performance," Financial Analysts Journal 42, no. 4 (July-August 1986): 39-48, Charloteville.

Conrad, J., and Kaul, G., 1998, "An anatomy of trading strategies," Review of Financial Studies, 11, pp. 489-519.

Dinov, I. 2005. "Introduction to Statistical Methods for the Life and Health Sciences" [Online] Available on 
http://www.stat.ucla.edu/ dinov/courses_students.html. (2010 Dec 27)

Damodaran, A. 2002. "Investment valuation: tools and techniques for determining the value of any asset" 2nd edition. Wiley Finance, New York.

Grinblatt, M., and Tobias J.M, 2003." Predicting stock price movement from the pattern of past return". Working paper, Chicago: University of Chicago.

Grinblatt, M. and Han, B., 2002." The disposition effect and momentum”. Working paper, NBER.

Grundy, BD; Martin,J.S., 2001, "Understanding the nature of the risks and the source of the rewards to momentum Investing" The Review of Financial Studies; spring.

Grinold, R. and Khan, R. 1999."Active Portfolio Management: A Quantitative Approach for Providing Superior Return and Controlling Risk". McGraw Hill, New York.

Goodwin, T. H. (1998), "The Information Ratio", Financial Analysts Journal, July/August, pages 34 to 43, Charloteville.

Griffin, J.M, Ji, X.Q, Martin, J.S, (2005), "Global Momentum Strategies: A Portfolio Perspective", Journal of Portfolio Management (Winter), 23-29.

Holmes, S. 2004. “Mann-Whitney U Test”. [Online] Available on http://www-

stat.stanford.edu/ susan/courses/s141/hononpara.pdf

$(2010$

Dec 27). 
Hong, H., Stein (1999)." A Unified Theory of undereaction, Momentum Trading and Overreaction in Asset Market" Journal of Finance, 54, 2143-2184.

Hou, K., 2001. "Information diffusion and asymmetric crossautocorrelations in stock return." Working paper, Ohio State University, Ohio.

Hong, H., Lim, T., and Stein,J.C. 2000. "Bad news travels slowly: size, analyst coverage and the profitability of momentum strategies", Journal of Finance 55, 265-295.

IDX Team, 2010. "Buku Panduan Indeks Harga Saham Bursa Efek Indonesia 2010". Indonesia Stock Exchange, Indonesia.

Ibbotson, R.G. and Kaplan, P.D. 2000 "Does Asset Allocation Policy Explain 40, 90, or 100 Percent of Performance?” Financial Analysts Journal 56, no. 1 (January-February 2000): 26-33, Charloteville.

Jegadeesh, N., and Titman, S., 2001, "Profitability of momentum strategies: An evaluation of alternative explanations," Journal of Finance, 54, pp. 699-720.

Jegadeesh, N., and Titman, S. 1993."Return to Buying Winners and Selling Losers: Implication for stock Market Efficiency."Journal of Finance, vol 48, no 1 (March):65-91.

Kahneman, D. and Tversky,A., 1979. "Prospect theory: an analysis of decision under risk". Econometrica 47, 263-291.

La Porta, R. 1996. "Expectations and the Cross-Section of Stock Returns". The Journal of Finance, Vol. 51, No. 5 (Dec., 1996), pp. $1715-1742$ 
Lee, C.M.C and Swaminathan, B., 2000. "Price momentum and trading volume”, Journal of Finance 55, 2017-2069, Charloteville.

Lakonishok, J. and Shleifer, A., and Vishny, R.W., 1994,"Contrarian Investment, Extrapolation, and Risk"Journal of Finance, Vol, 49, no 5 (December):1541-78.

Murphy, J.J., 1999. "Technical analysis of the financial markets: a comprehensive guide to trading methods and applications". New York: New York Institute of Finance.

O'Shaughnessy, L., 2004. The truths behind momentum investing: the theory works until you factor in trading cost. Http://www.financialadvisormagazine.com/articles/march_200 4_truth.html

Reilly, F.K. and Brown, K.C. 2006, Investment Analysis and Portfolio Management, Cengage, South-Western.

Reignganum, M., 1988.'The Anatomy of a Stock Market Winner". Financial Analysts Journal; Mar/Apr 1988; 44, 2;

Shefrin, H. 2007." Behavioral Corporate Finance-Decision That Create Value" New York: McGraw-Hills.

Sorensen, E.H., Keith, L.M., and Samak,V.“Allocating between Active and Passive Management," Financial Analysts Journal 54, no. 4 (September/October 1998): 18-31. 